\title{
LA FRONTERA COMO PEDAGOGÍA: ENSEÑANDO Y APRENDIENDO ACERCA DE FRONTERAS REMOTAS
}

\author{
FRANCISCO LARA-VALENCIA \\ Professor da Arizona State University \\ francisco.lara@asu.edu \\ DANIEL FURNISH \\ Mestrando na Arizona State University \\ drfurnis@asu.edu
}

Este capítulo presenta y discute un enfoque pedagógico y un método para generar una comprensión más completa de los espacios fronterizos entre estudiantes de nivel universitario. El enfoque propuesto está guiado por la noción de que la disección de los lugares fronterizos en sus diferentes componentes sociales y materiales, y su estudio en conexión con los procesos socio-espaciales generados por las fronteras internacionales, es la forma más eficaz de enseñar y aprender sobre estos lugares. Este enfoque asume que los estudiantes deben desempeñar un papel activo en el proceso de aprendizaje participando en actividades que conducen al descubrimiento y la estructuración de una nueva comprensión de la sociedad y el espacio. Por lo tanto, la función principal del profesor es facilitar el proceso suministrando y organizando las actividades de aprendizaje llevadas a cabo por los alumnos en el aula o en el campo. El profesor también actúa como coproductor y consumidor del nuevo entendimiento y conocimiento, lo que refuerza la integridad del proceso de aprendizaje y valida sus resultados.

\section{Enfoque y método de una pedagogía fronteriza}

El método utiliza tecnologías de visualización remota que permiten la exploración y comparación de lugares fronterizos en diversos entornos geográficos, económicos y políticos nacionales. La observación virtual de paisajes urbanos ha crecido en popularidad en disciplina como la geografía y planificación espacial durante las últimas décadas debido a la creciente cobertura y calidad la información geo-espacial disponible en plataformas como Google 
Earth y Google Maps. En el contexto de la epidemia del Covid-19, que ha migrado la enseñanza al internet y eliminado la posibilidad de trabajo de campo in situ, el valor de la metodología propuesta se ha magnificado. Google Earth, en particular, combina imágenes satelitales y conjuntos de datos geo-espaciales que cubren la mayoría de las ciudades y países del mundo y permiten a sus usuarios explorar y comparar localidades remotas con facilidad. A través de las imágenes y los datos geo-espaciales de Google Earth, los investigadores pueden observar, medir, analizar, e incluso rastrear cambios socio-espaciales. Aunque son ampliamente utilizados en los Estados Unidos y Europa, su utilización es menos común en los países en desarrollo, y rara vez se aplican en el estudio de espacios fronterizos.

En este capítulo se presentan y discuten las lecciones resultantes de la aplicación de esta estrategia pedagógica para el aprendizaje de las teorías del desarrollo espacial fronterizo y la dinámica transfronteriza. La implementación se dio en el contexto de un curso universitario donde el primer autor fue el instructor y su coautor un estudiante avanzado de posgrado. La presentación se organiza de la siguiente manera. En primer lugar, presentamos un resumen de la literatura existente sobre ciudades fronterizas para identificar los elementos que definen el carácter social y espacial único de estas urbanizaciones. Enseguida, describimos con cierto detalle el enfoque y el método utilizados en este ejercicio y sus resultados de aprendizaje luego de su aplicación en dos conurbaciones fronterizas en las fronteras México-Estados Unidos (Mexicali-Calexico) y Uruguay-Brasil (Rivera-Sant'Ana do Livramento). Por último, después de discutir nuestros hallazgos a la luz de las representaciones teóricas de lo que constituye un lugar fronterizo, llegamos a la conclusión de que este método es una manera eficaz de enseñar y aprender sobre el espectro de realidades fronterizas que producen distintas geografías nacionales, y la influencia singular de las fronteras internacionales en los paisajes urbanos.

\section{Lugares fronterizos}

Su ubicación limítrofe impone a las ciudades fronterizas un conjunto de condiciones que dan forma a su estructura espacial y patrón de desarrollo único (Buursink, 2001, Arreola, 1996). Como 
ha observado Agnew (2008) las fronteras son facilitadoras de diversos procesos sociales, económicos y políticos que tienen un efecto real y directo en las comunidades fronterizas, e influyen en la función, forma, estructura, centralidad y estabilidad de los lugares donde habitan. En última instancia, el hecho definitorio de los lugares fronterizos es que su existencia depende en gran medida de la frontera porque la condición limítrofe y la adyacencia hace que la interacción y la hibridación transfronteriza sean más directas e intensas que en otros lugares (Buursink, 2001). Sin embargo, como recuerda Paasi (2005), ni las fronteras ni las realidades espaciales y sociales que producen son únicas. Debido a que las fronteras son construcciones sociales con múltiples orígenes, trayectorias y significados, es poco probable que tengan "algún poder causal universal e independiente" capaz de dar forma a los lugares fronterizos como espacios indistinguibles (Paasi, 2005, p. 27). Más bien, debemos empezar aceptando que cada frontera, y cada espacio fronterizo que estas producen, tiene una esencia distintiva. El carácter distintivo de los lugares fronterizos es complejizado por la fluidez de la propia frontera. Aunque las fronteras nacionales son consideradas convencionalmente como líneas fijas y bordes de separación, la mayoría son permeables o porosas, y permiten diferentes grados de interpenetración y mezcla. La amplitud y profundidad de la interpenetración y la mezcla definen el carácter de los lugares fronterizos - su función, forma y estructura, pero también su identidad y personalidad como formaciones sociales. En consecuencia, las fronteras a menudo producen continuidades socio-espaciales que unen a las personas y lugares a través de la frontera, y transforman los pasos fronterizos en corredores que conectan ciudades y pueblos con el "otro lado." La permanencia de estas continuidades y conexiones se ve afectada por el contexto social más amplio, pero también por la fronterización, el proceso de construcción de las fronteras por medio de la "ideología, la mediación cultural, el discurso, las instituciones políticas, las actitudes y otras formas cotidianas de trascender y confirmar la frontera" (Scott, 2012, p. 87).

Dado que los lugares fronterizos varían significativamente de un contexto a otro, y de acuerdo con la dirección y la fuerza del proceso fundamental de fronterización, es importante destacar 
aquellos aspectos que los distinguen de los lugares no fronterizos. La literatura de estudios fronterizos, informada por una amplia gama de disciplinas académicas, como la geografía, la planificación, la economía y la sociología, proporciona una imagen completa de la función, forma, estructura e identidad de los lugares fronterizos.

En términos generales, la función de una ciudad está determinada por la naturaleza, variedad, y volumen de las actividades que tienen lugar dentro de sus límites y que conectan las necesidades de sus habitantes con procesos sociales y espaciales externos que ocurren a varias escalas. En el caso de las ciudades fronterizas, el elemento definitorio de la funcionalidad urbana es la adyacencia al límite exterior, lo que las transforma en lugares de movilidad, hibridación, y amplificación de procesos nacionales (Fuentes, 2000). La conexión con la frontera se manifiesta de muchas maneras, incluida la orientación externa de las ciudades fronterizas y su dependencia del comercio, los viajes, y el turismo como fuente de sus actividades económicas básicas (Sohn and Lara-Valencia, 2013). El tirón gravitacional de la frontera es más evidente en el ensamblaje de edificios, carreteras, puentes, muros y señalización alrededor de los pasos fronterizos y cuya función principal es regular la movilidad transfronteriza. Estos conjuntos han atraído durante mucho tiempo la atención de geógrafos y planificadores urbanos interesados en entender cómo las ciudades fronterizas hacen converger elementos nacionales e internacionales para crear paisajes urbanos singulares (Nugent, 2012, Herzog, 1991). Estos estudios nos dicen que la concentración de las expresiones materiales y simbólicas de la frontera es más alta alrededor de los puntos de cruce internacional, que, en muchos casos, también anclan el emplazamiento del centro comercial y de negocios de la ciudad (Arreola, 1996). Por lo tanto, una inspección visual del distrito central de muchas ciudades fronterizas revela el protagonismo de las instalaciones relacionadas con el comercio y los negocios orientados al turismo, las compras, y otros servicios que están directamente relacionados con la adyacencia de la frontera. La infraestructura para el control y la vigilancia de la movilidad transfronteriza también suele ser evidente en la cercanía de los puntos de cruce. 
Debido a que las ciudades fronterizas funcionan como puertas de entrada entre dos o más países que necesitan controlar el tráfico de mercancías y personas que entran o salen por sus fronteras, es común que ocurran en diadas (v. gr: El Paso-Ciudad Juárez) o tríadas urbanas (v. gr: Foz de Iguazú-Puerto Iguazú-Ciudad del Este). Como se mencionó anteriormente, cada urbanización fronteriza es única en muchos sentidos, y entender su forma y personalidad particulares desde una perspectiva urbana requiere mirar su origen, evolución y cultura (Tagil, 1982, Pounds, 1963). Algunos pares de ciudades fronterizas surgieron a lo largo de límites establecidos en territorios sin presencia cultural significativa previa, por lo que son en su mayoría un producto de la frontera misma. En algunos casos, las fronteras se delineaban teniendo en cuenta los patrones culturales y de asentamiento existentes, creando un lugar donde antes no existían. Otras ciudades fronterizas son el resultado de límites superpuestos negociados con poca consideración por la actividad humana previa, lo que en algunos casos resulta en la partición de asentamientos preexistentes (Morehouse, 2004).

Los pares de ciudades fronterizas, el tipo más común de urbanización fronteriza, operan como emplazamientos económicos que fluctúan con los cambios en diferenciales de precios, paridades monetarias, y costos de transacción. Los flujos continuos de personas y mercancías dentro y a través de las ciudades fronterizas justifican las funciones administrativas únicas que desempeñan en la regulación y el control del comercio y la movilidad humana. El hecho de que su economía esté fundamentalmente vinculada al movimiento transfronterizo de mercancías y personas exige la creación de la infraestructura material e institucional que apoya y regula dicho tráfico. En consecuencia, las ciudades fronterizas están material y socialmente dominadas por una densidad de instalaciones aduanales, puestos de control migratorio, mojoneras fronterizas, centros de transporte, además de todas las funciones y ocupaciones necesarias para la operación de dicha infraestructura.

Como sugiere Hanson (2001), debido a la presencia tangible de la frontera en la vida cotidiana de los ciudadanos y la adyacencia del país vecino, las ciudades fronterizas son laboratorios naturales en los que observar las consecuencias de los procesos fron- 
terizos. Dado que las fronteras no son meros bordes territoriales, sino instituciones complejas marcadas por tensiones entre las prácticas de reforzamiento fronterizo y movilidad transfronteriza, estas producen espacios que laten al ritmo de los flujos de personas, bienes e ideas, que a su vez pueden contribuir a la formación de identidades colectivas y comunidades transfronterizas (Sassen, 2008, Balibar, 2002). Según Bustamante (1989), estos espacios inducidos por la frontera se contraen y se expanden en respuesta al equilibrio entre las fuerzas de defronterización/refronterización, y cambian su configuración territorial, dimensiones, contenido y funciones dependiendo de qué fuerza ejerza la mayor influencia en un momento determinado. Dentro de estos espacios normalmente conviven múltiples paisajes urbanos fronterizos, operando simultáneamente y superponiéndose en diferentes momentos y lugares (Brambilla, 2015). Los procesos históricos subyacentes a la erección de la frontera; la defronterización, y la refronterización en el contexto de las globalizaciones, así como las consecuencias espaciales de estos vaivenes, están en el centro del análisis fronterizo contemporáneo (Scott, 2012).

\section{La frontera como recurso pedagógico}

Pasar de la mera comunicación de representaciones conceptuales de lugares fronterizos a un proceso de aprendizaje eficaz y substantivo exige considerar los desafíos de la enseñanza de las fronteras y su potencial como un recurso pedagógico en la educación universitaria.

\section{Las fronteras en la educación y como educación}

Como asignatura educativa, la enseñanza de los estudios fronterizos impone exigencias particulares a profesores y alumnos debido a la naturaleza polisémica y cambiante de la asignatura y a la fluidez del campo (Buursink, 2001, Scott, 2012). El desarrollo de una comprensión integral de las fronteras requiere una combinación de perspectivas históricas y teóricas tomadas de una variedad de disciplinas para compensar la falta de una teoría general de las fronteras. Esto plantea desafíos significativos tanto a los profesores como a los estudiantes que están obligados a hilvanar concep- 
tos y explicaciones de los fenómenos fronterizos dispersos y fragmentados en las disciplinas académicas de las ciencias sociales y las humanidades. Las fronteras son también un tema altamente ideológico, y las narrativas cargadas de puntos de vista emocionales y nacionalistas, que tienden a oscurecer la comprensión de las realidades fronterizas, son omnipresentes en los medios de comunicación. La falta de experiencia personal al universo diverso de realidades fronterizas entre los estudiantes universitarios, y la abundancia de información de los medios masivos de comunicación que sensacionaliza las fronteras, dejan a los maestros y estudiantes con el complicado reto de lidiar con representaciones distorsionadas de la situación real.

Desde una perspectiva pedagógica, los recientes avances en el campo de los estudios fronterizos son bastante prometedores. El estudio de las fronteras ha transitado en las últimas décadas de ser un campo centrado principalmente en la comprensión empírica de geografías y circunstancias fronterizas particulares a una empresa académica más preocupada por explicar las fronteras en general y su interacción con procesos multiescalares de cambio social (Anderson et al., 2002, Scott, 2012, Benedetti, 2014). En esta evolución, dos áreas significativas de investigación han ganado terreno dentro del campo de los estudios fronterizos. La primera área privilegia una visión de las fronteras como prismas capaces de absorber y refractar procesos sociales complejos, como la globalización, en sus dimensiones espectrales constitutivas como la integración económica, la gobernanza multinivel, las movilidades transfronterizas, la migración internacional, o la transformación de identidades culturales y nacionales. Desde esta perspectiva, y debido a su papel central en el emplazamiento y la regulación de procesos transnacionales, se plantea que las fronteras pueden ayudarnos a medir y comprender la intensidad, dirección y naturaleza del cambio de los sistemas globales, así como la influencia de las fuerzas económicas, políticas y culturales nacionales sobre estos sistemas (Sohn and Lara-Valencia, 2013).

La segunda área de investigación tiende a ver las fronteras como una fuerza generativa en sí misma, produciendo realidades sociales únicas resultantes del hecho de que en las fronteras a me- 
nudo convergen y entremezclan instituciones sociales y culturales que pertenecen a diferentes Estados nacionales. Desde este punto de vista, los estudios fronterizos se ocupan más de la tensión constante entre la separación y la conexión y su resolución en un espacio dialéctico que cristaliza en diferentes grados de interacción e integración transfronteriza. Fenómenos fronterizos bien conocidos, como la hibridación cultural y lingüística o la cooperación transfronteriza, son temas frecuentes en esta línea de investigación (Heyman, 2012). Cuestiones fronterizas como las disputas territoriales y los conflictos, o la formación de mercados subterráneos donde florecen el contrabando y otras actividades ilegales o ilícitas, también se abordan regularmente utilizando esta perspectiva (Tapia Ladino, 2017, Dorfman et al., 2017).

\section{Enseñar y aprender sobre fronteras}

La adquisición de conocimientos relacionados con el poder de las fronteras y los procesos fronterizos como espacio y mecanismos de configuración de lugares es más eficaz si los estudiantes pueden ver cómo operan estas fuerzas. Un examen sincrónico sería deseable, pero esto es una imposibilidad obvia. Una alternativa es un análisis comparativo de los lugares situados en geografías fronterizas distantes entre sí. Al contrastar ciudades fronterizas geográfica y contextualmente distantes, los estudiantes pueden generar conocimientos significativos para ellos porque les permiten ver la conexión entre las representaciones conceptuales de los procesos socio-espáciales característicos de las fronteras y su expresión en la morfología y el contenido material de estos lugares. Para los profesores, el análisis comparativo de las ciudades fronterizas distantes es un recurso pedagógico que facilita la disección de procesos complejos y multiescalares que convergen en los espacios fronterizos, y que van desde la globalización, las redes sociales transfronterizas, y las identidades locales. También ofrece oportunidades para enriquecer la enseñanza aprovechando las teorías y los conocimientos producidos en una variedad de campos disciplinarios y promover la comprensión interdisciplinaria de las fronteras.

Con esto en mente, se diseño una actividad de enseñanza-aprendizaje sobre fronteras. La actividad fue diseñada inicialmen- 
te como un experiencia de aprendizaje para una clase introductoria sobre estudios fronterizos, pero más tarde fue adaptada como un ejercicio para una clase avanzada en la que participaron estudiantes avanzados de pregrado y estudiantes de posgrado (Lara-Valencia, 2018). La actividad se basa en el examen sistemático de lugares fronterizos utilizando representaciones virtuales del espacio y sus elementos constitutivos. Por examen sistemático nos referimos a que el ejercicio fue diseñado para hacer posible que los estudiantes descubrieran por si mismos la centralidad de la frontera en la organización socio-espacial, y configuración de lugares fronterizos seleccionados mediante la identificación de elementos funcionales, morfológicos, institucionales y simbólicos indicativos de algún tipo de interacción e integración transfronteriza (cuadro 1).

El dominio funcional registra aquellas actividades que manifiestan la interacción entre las economías y las sociedades coadyacentes a la frontera, como las compras, el turismo, el empleo, la asistencia a la escuela, el comercio, y otras actividades que implican flujos regulares de personas a través de la frontera. La existencia de tales flujos refleja complementariedades, y potencialmente cierto grado de interdependencia. Los elementos de forma se relacionan con las características del entorno construido que expresan el papel de los lugares fronterizos como el sitio principal para la movilidad y la interacción que conecta a las personas y las economías a través de las fronteras. Los puntos de control, los túneles, los puentes y la señalización direccional son ejemplos de estas características. El uso del lenguaje, el arte público y los rasgos arquitectónicos son elementos del dominio cultural. Este dominio se constituye de las expresiones ideacionales y simbólicas que expresan el arraigo de las personas a los valores e identidades nacionales en general, y hacia las comunidades e instituciones del otro lado de la frontera.

La actividad es virtual por que los estudiantes no necesitaban estar físicamente presentes en el lugar para llevar a cabo el examen sistemático del espacio fronterizo. La actividad se basa en 


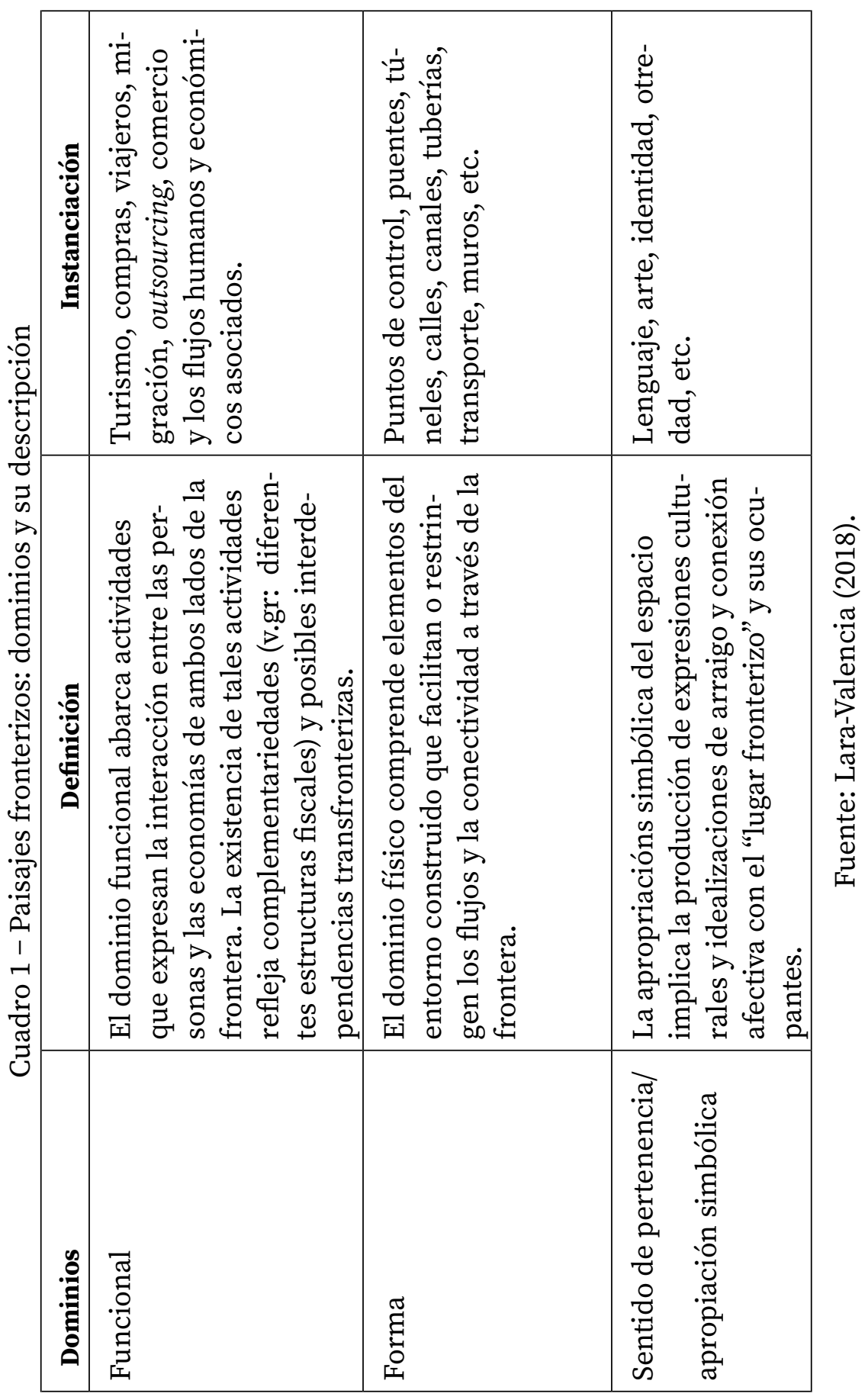


imágenes de Google Earth Pro, que permiten a los estudiantes realizar la exploración virtual de ubicaciones remotas. Google Earth Pro es una plataforma digital que combina mapas convencionales con imágenes satelitales y fotografía aérea de alta resolución (Russell, 2019). La plataforma permite la integración de datos de Sistemas de Información Geográfica (SIG) que, combinados con su capacidad para leer y generar datos en formato KML (Keyhole Markup Language), facilita tareas educativas como el intercambio de datos y el trabajo en equipo. Los mapas de Google Earth Pro se enriquecen con información sobre topografía, red de calles, edificios públicos, parques, iglesias y otros lugares de interés local. Las imágenes aéreas se actualizan periódicamente; por lo tanto, la información disponible a través de la plataforma es generalmente reciente (Russell, 2019). Además de las imágenes aéreas, Google Earth también incluye Street View, una utilería que proporciona imágenes panorámicas tridimensionales a nivel de calle de $360^{\circ}$ de lugares urbanos del mundo (Vandeviver, 2014). Cabe señalar que la actualidad, cobertura y resolución de las imágenes disponibles a través de Street View para ciudades en América del Norte, Europa y Japón son significativamente mejores que las imágenes disponibles para ciudades del resto del mundo. En estas otras ciudades las imágenes de Street View producidas por Google tienden a concentrarse en vialidades primarias y distritos comerciales y turísticos.

El uso de tecnología de visualización remota permitió la inmersión virtual de los estudiantes en territorios fronterizos remotos, de los que pudieron ver calles, negocios, hogares, colores, formas, idiomas, mojoneras, y otros elementos urbanos; y visualizar la configuración del lugar. Ver la frontera, exponerse a las continuidades y rupturas que produce, es una manera eficaz de descubrir lo que es distintivo de los lugares fronterizos y lo que comparten con otras ciudades y pueblos. También proporciona a los estudiantes los elementos necesarios para formular sus propias preguntas y promueve la reflexividad, un resultado educativo particularmente deseable cuando la enseñanza tiene que superar los conceptos erróneos arraigados sobre los lugares fronterizos. 


\section{Ver la frontera}

Para evaluar la aplicabilidad y el valor pedagógico del enfoque y método descritos anteriormente, el segundo autor de este capítulo se ofreció a explorar la estructura espacial y el paisaje urbano de dos pares de ciudades fronterizas: Mexicali-Calexico en la frontera entre México y Estados Unidos, y Rivera-Sant'Ana do Livramento en la frontera entre Uruguay y Brasil. La exploración fue parte de una actividad de aprendizaje diseñada para enseñar a los estudiantes universitarios la primacía de la frontera en la organización de la función, forma, e identidad urbana de estos dos pares de ciudades geográfica y contextualmente remotas. Otros estudiantes en el curso exploraron otras ciudades en la frontera entre Estados Unidos y México, pero su trabajo no se examina en este capítulo.

El ejercicio requirió la identificación y caracterización de las actividades urbanas alrededor de los puntos fronterizos de entrada, haciendo hincapié en el examen de los patrones de densidad y dispersión de elementos funcionales, morfológicos y simbólicos típicos de los lugares fronterizos. El ejercicio se apoyó en el uso de una matriz de observación para registrar la distribución y concentración de las actividades urbanas, la infraestructura de movilidad, la tecnología de control y vigilancia, y los símbolos culturales y lingüísticos de la interacción fronteriza (figura 1). La matriz demarca una circunferencia de $500 \mathrm{~m}$ de radio centrada alrededor del punto de cruce fronterizo principal que conecta cada par de ciudades. Cada mitad de la matriz se subdivide en cuatro secciones o cuadrantes de igual tamaño.

\section{Mexicali, México y Calexico, Estados Unidos}

Tanto Mexicali como Calexico se localizan en un valle agrícola muy fértil y bien irrigado. Visto desde arriba, sin embargo, es evidente la disparidad significativa en tamaño y desarrollo entre ambas ciudades: la "forma piramidal" invertida de Mexicali, cortada bruscamente por la frontera, aunque "abrazándola" de cerca, cubre casi por completo el lecho del valle, mientras que Calexico es un rectángulo relativamente pequeño rodeado de campos agrícolas delineados simétricamente. 


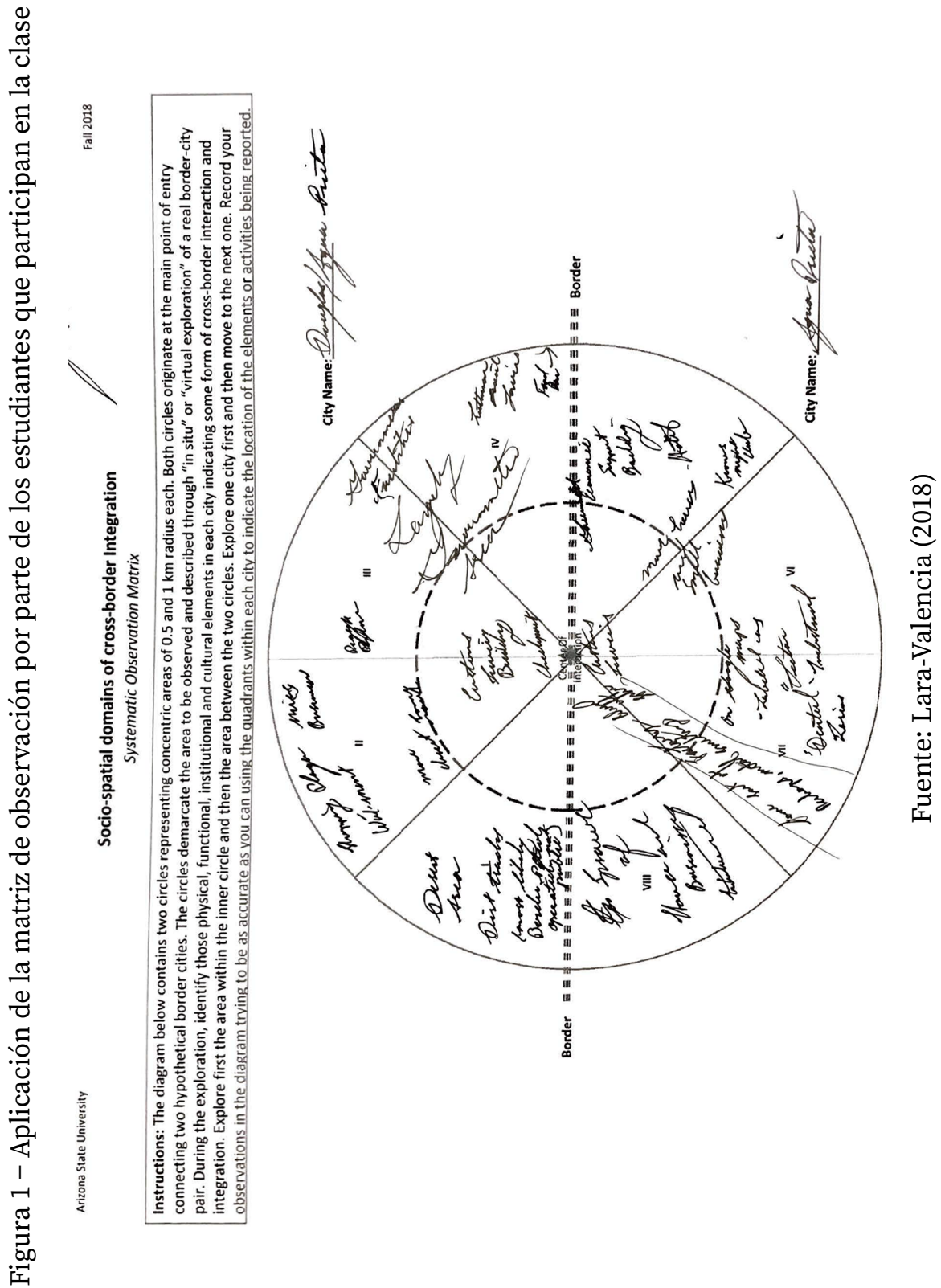


Durante una época, Mexicali fue un gigante de la industria del algodón, pero desde la década de 1960, se ha convertido progresivamente en un centro de producción industrial dominado por maquiladoras, plantas de ensamblaje que operan para corporaciones estadounidenses como Honeywell, Kellogg's, Gulfstream, UTC Aerospace Systems, Rockwell Collins, LG Electronics, Mitsubishi, Autolite, Robert Bosch y Goodrich Corporation entre otras. La transformación económica experimentada por la ciudad de las últimas década ha repercutido en grandes flujos migratorios atraídos por el empleo industrial, lo que a su vez ha sido el motor de un proceso de urbanización rápida (James, 2018). Reforzado por la promulgación del Tratado de Libre Comercio de América del Norte (TLCAN) a principios de los años 90s, el crecimiento industrial de Mexicali redundó en un aumento poblacional de 330,000 habitantes entre 1990 y 2010, mientras que la población de Calexico sólo creció en 19,000 durante el mismo periodo (Lara-Valencia, 2013). La celeridad de la transformación económica de Mexicali ayuda a contextualizar la disparidad general en el tamaño y la densidad del desarrollo de cada ciudad, aunque también explican los rasgos agrícolas que se observan todavía en las imágenes satelitales del par fronterizo.

El epicentro de la interacción entre las dos ciudades es el cruce fronterizo, donde la Estación de Inspección Fronteriza de los Servicios de Aduanas e Inmigración del Estados Unidos (USCIS por sus siglas en inglés) es la estructura más dominante (figura 2). Se trata de un edificio de tres pisos emplazado directamente sobre la frontera y que debido a su volumen empequeñece los otros edificios de Calexico y al edificio de la Aduana Mexicana y del Instituto Nacional de Migración (INM) en Mexicali. A menos de 50 metros del puerto de entrada se observan las vías férreas por las que transitan trenes que transportan carga entre los dos países, un indicador de creciente movimiento de mercancías facilitado por el TLCAN y las maquiladoras.

Por supuesto, el polémico muro fronterizo de Estados Unidos se extiende tanto al este como al oeste desde este punto, separando abruptamente las dos ciudades. En el lado norte del muro, en el espacio abierto entre Calexico y el muro, hay 
reflectores colocados a intervalos regulares de aproximadamente 80 metros. Vehículos oficiales de la Oficina de Aduanas y Protección Fronteriza (CBP por sus siglas en inglés) y de la Patrulla Fronteriza (USBP por sus siglas en inglés) aparecen ocasionalmente en el paisaje cuando se observa a través de Google Street-View. En contraste, hay poca o ninguna vigilancia en el lado sur del muro, ya que Mexicali se apretuja firmemente contra el límite internacional, dejando poco o ningún espacio entre la ciudad y el límite internacional. De hecho, en Mexicali, hay signos visibles de un esfuerzo deliberado y concertado para manejar esta asimetría en la securitización del espacio, incluyendo infraestructura vial para ordenar y canalizar el tráfico que espera cruzar a Estados Unidos y anuncios que indican el tiempo de espera y las horas de operación de los carriles SENTRI ${ }^{1}$.

Una de las impresiones más inmediatas generadas por el análisis del espacio circundante al puerto fronterizo es la diferencia en la presencia y densidad de la actividad residencial. En Calexico, hay aproximadamente 18 manzanas residenciales (definidos como desarrollos residenciales de 0.5 a 1.5 hectáreas), ubicados en los bordes exteriores de los cuadrantes III y IV de la matriz de observación. La mayoría de estas manzanas parecen contener viviendas típicas de las ciudades del medio oeste de los Estados Unidos: viviendas unifamiliares o dúplex, con una vivienda que ocasionalmente se divide en dos unidades en cada predio. La mayoría de estas unidades aparentaban estar ocupadas al momento de la recopilación de estos datos a través de Google Earth, ya que había coches al frente de la mayoría de las viviendas. Un número de predios en esta área se encuentran en estado natural o abandonados.

1 La Red Electrónica Segura para la Inspección Rápida de Viajeros (SENTRI, por sus siglas en inglés) es un programa de la Oficina de Aduanas y Protección Fronteriza (CBP) de los Estados Unidos que otorga el derecho de usar un carril de cruce rápido a aquellos a viajeros que pagan una precertificación como viajeros seguros. El acrónimo SENTRI es fonéticamente similar al vocablo Sentry, que en inglés significa centinela o guardia que controla el movimiento de personas a través de un paso o puente. 
Figura 2 - Vista aérea de la urbanización fronteriza Mexicali-Calexico

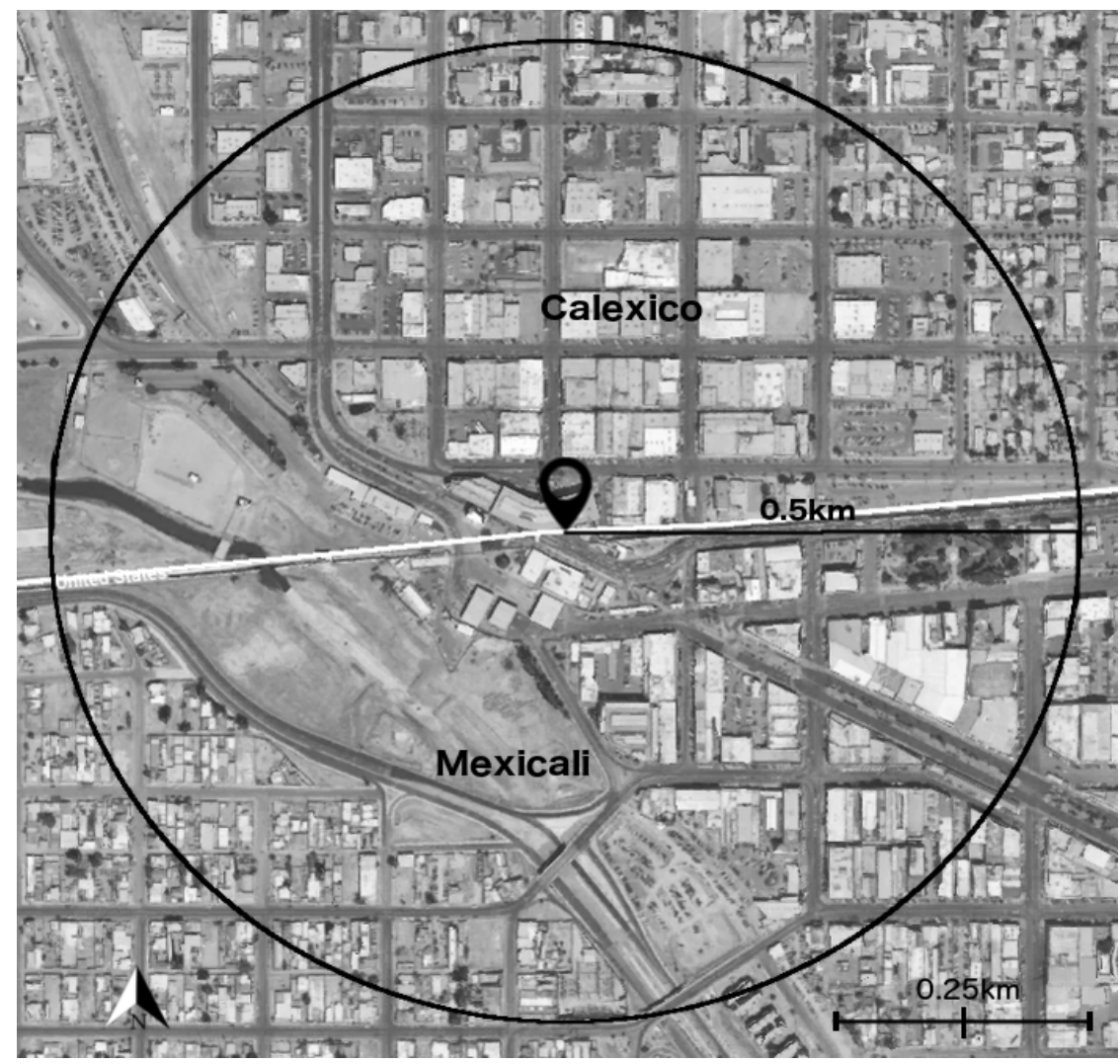

Fuente: Google Earth, 2020

En Mexicali - en las mitades exteriores de los cuadrantes VII y VIII - hay aproximadamente 60 manzanas residenciales. Estas manzanas registran un desarrollo de mayor densidad, ya que a menudo contienen múltiples viviendas unifamiliares dentro del mismo predio, y ocasionalmente apartamentos de dos pisos o pequeños negocios en las esquinas. Varios de estos lotes están desocupados o abandonados. Por último, hay diez manzanas en estado natural en la zona. Otras actividades urbanas de interés incluyen parques y otros espacios públicos que por sus características aluden a terceras culturas en ambas ciudades. El Parque Héroes de Chapultepec, en el cuadrante V, es yuxtapuesto por el Parque de la Amistad Fronteriza de Calexico en el cuadrante I. Una pagoda y el Barrio de 
la Chinesca son testimonio material de la importancia de la comunidad y cultura china en Mexicali.

Cuadro 2 - Prevalencia observada de actividad no-residencial en Mexicali y Calexico

\begin{tabular}{|l|c|c|c|c|c|}
\hline & \multicolumn{2}{|c|}{ Mexicali } & \multicolumn{2}{c|}{ Calexico } & Diferencia \\
\hline $\begin{array}{l}\text { Tipo de actividad } \\
\text { predominante }\end{array}$ & $\mathrm{N}$ & $\%$ & $\mathrm{~N}$ & $\%$ & $\%$ \\
\hline $\begin{array}{l}\text { Comercio } \\
\text { minorista }\end{array}$ & 39 & $35.8 \%$ & 59 & $51.8 \%$ & $-16.0 \%$ \\
\hline Servicios médicos & 18 & $16.5 \%$ & 3 & $2.6 \%$ & $13.9 \%$ \\
\hline Entretenimiento & 13 & $11.9 \%$ & 3 & $2.6 \%$ & $9.3 \%$ \\
\hline Servicios Legales & 0 & $0.0 \%$ & 9 & $7.9 \%$ & $-7.9 \%$ \\
\hline $\begin{array}{l}\text { Servicios } \\
\text { alimentarios }\end{array}$ & 15 & $13.8 \%$ & 7 & $6.1 \%$ & $7.6 \%$ \\
\hline Otro & 24 & $22.0 \%$ & 33 & $28.9 \%$ & $-6.9 \%$ \\
\hline Totales & 109 & & 114 & & \\
\hline
\end{tabular}

Fuente: Google Maps, 2020.

Un examen más minucioso sugiere que el área está dominada por actividades no residenciales. Sin embargo, cada ciudad muestra diferencias significativas en densidad, tipo y organización. En Mexicali, Google Maps indica la presencia de 109 estructuras individuales no residenciales, mientras que, en Calexico, el área contenía 114 sitios comerciales, gubernamentales y públicos 'registrados en Google' (Cuadro 2). Las diferencias más significativas entre las dos ciudades son que Mexicali tiene un 14.2\% más de servicios médicos, un $9.3 \%$ más de entretenimiento y un $7.7 \%$ más de servicios de alimentación que Calexico. Al mismo tiempo, Calexico muestra un $16 \%$ más de tiendas de ropa, un $7.9 \%$ más de servicios jurídicos y un 7.3\% más de todas las demás categorías combinadas. Los desarrollos no residenciales en la categoría "otros" no mostraron individualmente diferencias significativas, excepto en el caso de las instalaciones públicas, que se discutirán más adelante. 
Los anuncios que se observan en las fachadas de negocios y en las vías públicas de Calexico a menudo incluyen mensajes y direcciones en español. Estos negocios incluyen predominantemente tiendas de ropa, mueblerías, tiendas de tecnología y telefonía celular, joyerías, y oficinas que ofrecen servicios legales como el registro de vehículos. Los anuncios en Mexicali emplean principalmente el español, con el inglés utilizado en negocios específicos, principalmente en farmacias, y en mensajes en la vía pública relacionados con el cruce de la frontera.

\section{Rivera, Uruguay y Sant'Ana do Livramento, Brasil}

Situadas en un segmento de frontera seca entre Brasil y Uruguay, Rivera y Sant'Ana do Livramento son la mayor conurbación compartida por estos dos países a lo largo de 1,068 kilómetros. En 2010, Rivera-Livramento era un complejo urbano de unos 180,000 habitantes, con el 57\% de esa población viviendo en el lado uruguayo (Magri et al., 2017). La frontera internacional apenas está demarcada y serpentea a través de la red vial de ambas ciudades, produciendo una sensación de continuidad física e integración. La frontera actual se estableció durante la segunda parte del siglo XIX, pero los primeros signos de urbanización en la región coinciden con la instalación de plantas de sacrificio y producción de carne seca durante las primeras décadas del siglo XX (da Costa Braga and Rigatti, 2009). Después de la Segunda Guerra Mundial, la región entró en un período de estancamiento económico y crecimiento limitado de la población. A mediados de los años 1990s, Uruguay aprobó una legislación que permitía las tiendas duty free a lo largo de la frontera, mientras que Brasil hizo lo mismo en 2012 (Rodríguez Miranda, 2010, Odone and Sartori de Almeida Prado, 2015). En la actualidad, los motores económicos de la región son la industria de la hospitalidad (restaurantes, hoteles y casinos), las tiendas dury-free y las actividades minoristas que atraen compradores del interior de Brasil y Uruguay, quienes llegan atraídos, por los impuestos más bajos y el acceso a los productos importados (da Costa Braga and Rigatti, 2009).

Ambas ciudades dependen en gran medida de los flujos de personas y bienes que convergen y cruzan la frontera, que a su vez fluctúan con las variaciones del tipo de cambio y los ánimos 
políticos en Brasil y Uruguay. Los dispositivos de control y vigilancia son mínimos o no existen en esta zona fronteriza. Como describió Rey a mediados del siglo pasado, las mojoneras fronterizas son "de tan infimo tamaño que cualquiera puede confundirlos con una espita que separa los canteros de flores - plantados a lo largo de las calles Sarandí y Andrades," las dos avenidas que marcan el límite entre Uruguay y Brasil (Rey, 1948, p. 164).

La primera impresión que produce la imagen satelital de Rivera/Livramento, es que parecen ser una ciudad continua que se sobrepone a la frontera. La conurbación parece estar situada en un gran valle agrícola, con asentamientos más pequeños que se desprenden del centro urbano en todas las direcciones. Aparte de la avenida que corre directamente sobre casi toda la extensión urbana de la frontera internacional, a menudo separadas por un camellón verde que conecta mitad de la avenida que corresponde a cada país, hay poca o ninguna infraestructura que signifique la frontera y una completa falta de cualquier mecanismo de seguridad, vigilancia o control entre las dos naciones. La orientación del reticulado urbano está ligeramente sesgado, aunque en su mayor parte corre perpendicularmente al límite dando la impresión de un tejido urbano unificado. Sin embargo, si uno se posicionara directamente sobre la frontera internacional (a lo largo de la mencionada avenida), podría distinguir cada país por el idioma que adorna los escaparates de los negocios (español en lado de Uruguay y portugués en el lado brasileño) y por el cambio en la nomenclatura de calles que se extienden de manera ininterrumpida a través de la frontera.

El centro de interacción de la matriz de observación está situado sobre la Fonta Luminosa, una fuente que se asienta directamente sobre la línea internacional, y es el centro de un parque público compartido llamado Praça Internacional o Plaza Internacional Frontera de Paz (Figura 3). No hay valla, muro o puerto de entrada formal, y la infraestructura construida parece celebrar la proximidad de las dos ciudades, ya que el espacio fronterizo está ocupado por un espacio público que está abierto a ambos lados de la frontera internacional, y que esta adornado con varios monumentos y obras de arte público. Existen, sin embargo, un par de astas bandera que están situadas lado a lado sobre la línea internacional, cada una on- 
Figura 3 - Vista aérea de la urbanización fronteriza Rivera-Livramento

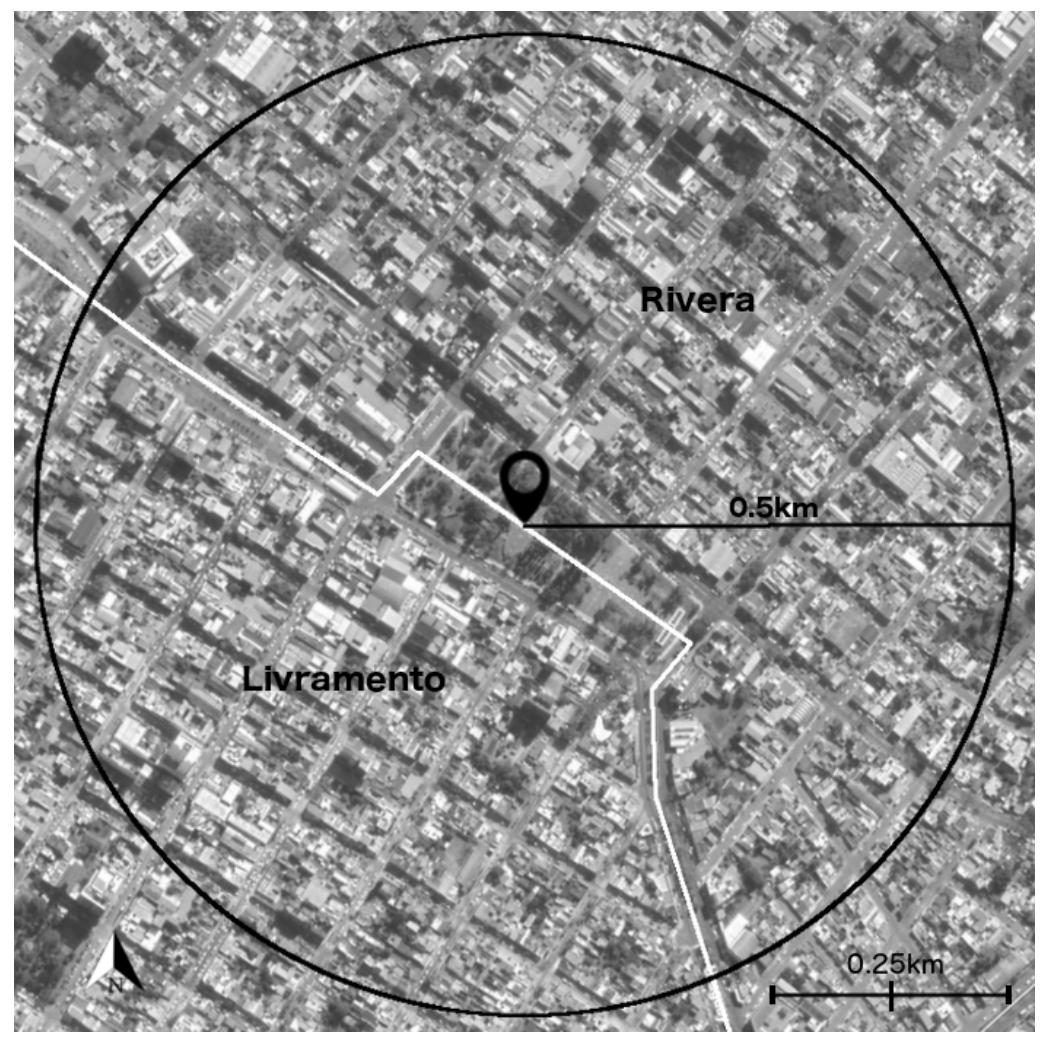

Fuente: Google Earth, 2020.

deando la bandera nacional de su respectivo país. Por último, cada país tiene un consulado en la ciudad vecina, situado virtualmente uno frente al otro, pero separados por la Plaza Internacional.

Debido al carácter compacto del tejido urbano de toda la zona, determinar la densidad residencial a través de una "mirada virtual" es problemático. Hay algunos indicios de mayor densidad residencial en Livramento, como parece sugerirlo la presencia de escuelas y edificios más altos. Dicho esto, la gran mayoría de los cuadrantes I y II en Livramento contienen-edificios no residenciales de varios pisos (hoteles y edificios de oficinas) y edificios residenciales de varios pisos con tiendas comerciales a nivel del suelo. Los cuadrantes III, IV y VI contienen más actividad residencial y comercial mixta 
dominada por edificios de una o dos plantas, para luego dar paso a un espacio residencial más homogéneo con unos cuantos negocios minoristas en las esquinas. Del mismo modo, la mayoría de los cuadrantes VII y VIII de Rivera son edificios comerciales de dos a tres pisos, con algunas construcciones de gran altura, la mayoría de los cuales cuentan con tiendas comerciales a nivel de la calle. Aparte de la concentración de actividad comercial cerca del parque, la mayor parte del cuadrante VI contiene edificios residenciales de uno a dos pisos, con algunas tiendas y otros negocios en las esquinas.

Usando la información de negocios y servicios "registrados en Google", se identificaron un total de 167 unidades no residenciales en la sección de la matriz correspondiente a Rivera. En contraste, Livramento registro 302 sitios comerciales, de servicios, minoristas, y gubernamentales. Considerando la diferencia en superficie terrestre, se estimó que hay aproximadamente 613 entidades no-residenciales por kilómetro cuadrado en el lado de la matriz que corresponde a Livramento y 572 por kilómetro cuadrado en el lado de Rivera. Si bien el desarrollo comercial es similar en ambos lados de la frontera, como es el caso de los servicios de alimentos, la industria del entretenimiento, las instituciones financieras, las agencias gubernamentales y los servicios médicos, existen diferencias significativas en los tipos específicos de empresas que son comunes en cada ciudad. Las diferencias más significativas se presentan en el Cuadro 3. Aquí, los datos muestran que había alrededor de un 13\% más de negocios minoristas en la parte de La matriz de Rivera al momento de la investigación. El segmento más significativo del comercio minorista de Rivera está representado por las tiendas "duty-free" que bordean las calles principales del distrito comercial de Rivera (alrededor del 40.9\% de las tiendas minoristas en la parte de la matriz de Rivera). Por el contrario, no se encontraron tiendas libres de impuestos en el lado de Livramento. Las tiendas libres de impuestos en Rivera anuncian sus mercancías igualmente en portugués, inglés y español. En Livramento, por otro lado, hay alrededor de un $17.7 \%$ más negocios relacionados con automóviles y transporte, incluyendo tiendas de autopartes, concesionarios de automóviles, y servicios de taxi. 
Cuadro 3 - Prevalencia observada de actividad no-residencial en Rivera-Livramento

\begin{tabular}{|l|c|c|c|c|c|}
\hline & \multicolumn{2}{|c|}{ Rivera } & \multicolumn{2}{c|}{ Livramento } & $\neq$ \\
\hline Tipo de actividad predominante & $\mathrm{N}$ & $\%$ & $\mathrm{~N}$ & $\%$ & $\%$ \\
\hline Comercio minorista & 93 & 55.7 & 129 & 42.7 & 13.0 \\
\hline $\begin{array}{l}\text { Venta al por menor libre de } \\
\text { impuestos }\end{array}$ & 38 & 22.8 & 0 & 0.0 & 22.8 \\
\hline $\begin{array}{l}\text { Venta al por menor relacionado } \\
\text { con el comercio }\end{array}$ & 3 & 1.8 & 27 & 8.9 & -7.1 \\
\hline Otros negocios minoristas & 52 & 31.1 & 102 & 33.8 & -2.6 \\
\hline Hoteles & 4 & 2.4 & 22 & 7.3 & -4.9 \\
\hline Servicios alimentarios & 23 & 13.8 & 47 & 15.6 & -1.8 \\
\hline Otro & 47 & 28.1 & 104 & 34.4 & -6.3 \\
\hline Totales & 167 & & 302 & & \\
\hline
\end{tabular}

Fuente: Google Maps, 2020.

Las diferencias restantes recogidas en la categoría "otros" de este análisis incluyen escuelas, clubes sociales y servicios comerciales o industriales. En suma, la dimensión socio-espacial más llamativa de esta frontera es que las diferencias entre las dos ciudades son sutiles, y el entorno construido se siente más como una sola ciudad continua que como expresiones de dos proyectos nacionales diferentes. Aun así, algunos indicadores marcan cada espacio como único e interdependiente en la interacción transfronteriza. Quizá debido a la ausencia de dispositivos de control fronterizo ostensibles, hay muy pocos signos de diferenciación que puedan ser observados con el método utilizado en este ejercicio.

\section{Discusión}

Estudios previos sobre el efecto de la frontera en el desarrollo y estructuración socio-espacial de las zonas adyacentes validan y contextualizan las observaciones realizadas tanto en Mexicali-Calexico como en Rivera-Livramento. Las marcadas diferencias en el patrón de desarrollo de Calexico y Mexicali (como se visua- 
liza en las imágenes aéreas y a nivel de calle de Google Earth), así como las disparidades y carácter unilateral de la securitización, control, y vigilancia, dialogan con la literatura que destaca la naturaleza asimétrica de la relación entre Estados Unidos y México. Griswold (2006) y Moyano (2006), por ejemplo, detallan la historia del conflicto que produjo la definición del límite internacional actual, comenzando con la guerra entre ambos países, y la posterior imposición de la frontera a través del Tratado de Guadalupe-Hidalgo (1848) y el Tratado de la Mesilla (1853). La relación entre los dos países registra una historia de tensión a lo largo del siglo XX, que se ha recrudecido en las últimas décadas y ha resultado en un marcado aumento de los controles a la movilidad en dirección norte y la construcción mediática de México como una amenaza para los Estados Unidos para justificar la militarización de la frontera.

Heyman (2012) reconoce que, si bien las expresiones contemporáneas de asimetría en esta frontera tienen profundas raíces socio-históricas, también son el producto de divergencias en el desarrollo cultural y político de cada nación, lo que resulta en la creación de modos distintos de gobernanza y gestión económica y social. Esta asimetría histórica es quizás la razón por la que es cuestionable la idoneidad del término "ciudades gemelas" para describir los desarrollos urbanos que se han producido a lo largo de la frontera entre Estados Unidos y México (Buursink, 2001). Esta historia de conflicto se manifiesta con ironía cuando se pone en conversación con algunas de los elementos urbanos observados en la proximidad del principal paso fronterizo de Mexicali y Calexico: El Parque Héroes de Chapultepec en Mexicali y el Parque de la Amistad Fronteriza en Calexico. El Parque Héroes de Chapultepec es un espacio arquitectónico que alude directamente a la Guerra México-Estados Unidos, mientras que el Parque de la Amistad Fronteriza proyecta una actitud de conexión y apertura, aunque habría que atravesar la frontera (a través de un muro o a través de un puesto de control migratorio) para moverse de un parque a otro. Juntos, estos dos parques son una expresión material indiscutible de la naturaleza asimétrica, y de la compleja interacción entre las dos naciones dentro de los confines de sus ciudades fronterizas.

La conexión entre ambos lados se expresa también en la elevada concentración de actividad comercial alrededor del puerto 
fronterizo, y que tanto en Mexicali como en Calexico exhibe una fuerte orientación hacia una base de clientes localizada del otro lado de la frontera. La alta prevalencia de tiendas minoristas en Calexico sugiere que gran parte de la economía local está dirigida a atender la demanda de consumidores de México. La dirección del flujo de consumidores parece revertirse, sin embargo, en el renglón de los servicios de salud, ya que Mexicali presenta una proporción mucho mayor de servicios médicos, dentales y farmacéuticos. La orientación externa de estos negocios es manifiesta en el uso del inglés en las fachada de consultorios y farmacias y es validada por estudios que analizan el rápido crecimiento de los "servicios médicos turísticos" en las ciudades mexicanas de la frontera en respuesta a la falta de seguro médico universal en Estados Unidos (Oberle and Arreola, 2004). La prevalencia mayor de servicios de alimentos y entretenimiento en Mexicali podrían atribuirse al carácter metropolitano de la ciudad, pero también a diferencias legales en cada país. Por ejemplo, la edad mínima legal para el consumo de alcohol en México es tres años menor que en Estados Unidos, lo que junto con la oferta de juegos de azar, explica un importante flujo de visitantes a centros de entretenimiento y restaurantes desde Calexico, El Centro y otras localidades en el Valle Imperial.

Si bien el término ciudades gemelas puede no ser apropiado en el contexto de las ciudades fronterizas de la frontera México-Estados Unidos, las ciudades de Livramento y Rivera parecen ser un buen epitome de la metáfora (Tapia Ladino, 2017). La falta de seguridad y control a lo largo de la frontera, y el nivel relativo de simetría en el entorno construido, no solo permite una alta movilidad transfronteriza, sino que crea una apariencia de integración y congruencia espacial que hace difícil distinguir una ciudad de la otra a simple vista. Esta ambigüedad territorial tiene raíces también en la historia regional. Da Costa Braga y Décio Rigatti (2009) describen cómo este par fronterizo ha disfrutado de una larga tradición de desarrollo transfronterizo simétrico, a pesar de que Uruguay no fue reconocido como una nación independiente hasta 1848 y la frontera actual no se estableció hasta el siglo XIX. Posteriormente, cada nación ha construido "redes urbanas complementarias" a lo largo de la frontera para mantener el equilibrio en los respectivos niveles de poder nacional dentro del espacio fronterizo. De particular interés en esta 
historia es la utilización transfronteriza del otrora espacio vacío entre ciudades limítrofes a lo largo de la frontera como una oportunidad para la socialización, donde los residentes de cada país podrían reunirse para convivir o jugar. Estas prácticas sociales, con raíces en la cultura Gaucha que valora el espacio abierto, se manifiestan en el Parque Internacional Frontera de Paz. De hecho, da Costa Braga y Rigatti (2009) dan cuenta de la importancia de la cooperación binacional en los procesos de planificación urbana regional, incluyendo la coordinación del emplazamiento de los servicios de seguridad pública y bienestar social, y la celebración de la unidad entre las dos ciudades. Es este tipo singular de cruce cotidiano, generativo y normalizado, de la frontera por personas que han habitado el lugar por generaciones lo que ha ayudado a la co-proproducción de una frontera relativamente abierta, independientemente del potencial de fricción bilateral, entre los proyectos nacionales respectivos de Brasil y Uruguay (Tapia Ladino, 2017).

Por último, es esencial reconocer que, a pesar de la falta de seguridad y control fronterizo y del grado de integración binacional dominante, "la disposición [de estas culturas] de vivir juntas y en armonía entre dos nacionalidades no implica una identidad compartida” (Da Costa Braga y Rigatti, 2009, p. 6). La profunda historia dejada en la región por los proyectos coloniales y la formación del estado-nación importan tanto en esta frontera como en la frontera México-Estados Unidos. Entender como estos procesos moldearon el desarrollo fronterizo es crucial para entender la cultura regional contemporánea de cualquier lugar de frontera (Heyman, 2012). Además, es importante recordar que el contexto cultural y social que existe dentro de Livramento-Rivera no es monolítico ni estático, sino una realidad fluida y compleja (Heyman, 2012).

\section{Lecciones vividas}

Hoy en día las fronteras no son simples marcadores de provincias geopolíticas, sino instituciones complejas que producen realidades multiescalares de integración y separación impresas en la vida de las ciudades fronterizas. Como sugieren Mezzadra y Neilson (2013, p. 3) las fronteras se han transformado en "instrumentos finamente sintonizados para gestionar, calibrar, y gobernar el movimiento global de personas, dinero y cosas" y al hacerlo, 
conectan y separan. Por lo tanto, incluso cuando el origen de la frontera define la configuración inicial de los pares de ciudades fronterizas, las fronteras contemporáneas son facilitadoras de espacios urbanos caleidoscópicos, es decir, ciudades donde lo nacional y lo extranjero cohabitan, y donde las identidades monolíticas que distingue entre el espacio que es "nuestro" y el espacio que es de "ellos" son desafiadas continuamente. De hecho, las pruebas que respaldan la noción de que las fronteras son sistemas multicapa, multifacéticos, mutables, y complejos se ha acumulado en la última década, proporcionando un renovado vigor a la necesidad de un conocimiento más preciso sobre los efectos de las fronteras nacionales en las ciudades fronterizas (Buursink, 2001).

El análisis socio espacial de Mexicali/Calexico y Rivera/Livramento ha producido evidencia irrefutable de interacción transnacional, aunque a través de diferentes canales y en magnitudes distintas debido a contexto socio-histórico específico en cada lugar. Debido a que Mexicali y Calexico son urbanizaciones contiguas e interdependientes, pero divididas crudamente por una valla fronteriza, Benedetti (2014) probablemente clasificaría a este par urbano como una "conurbación internacional", una categoría en la que el desarrollo a un lado de la frontera ha superado al otro en un intento de aprovechar la "movilidad" de bienes comerciales, mano de obra y personas; una recurso que capitalizan muchos lugares de frontera. Livramento y Rivera, por otro lado, podría caracterizarse como una "aglomeración binacional", bajo la cual "la ausencia de discontinuidades físicas marcadas" hace casi imposible distinguir entre dos ciudades, un rasgo que es común entre las ciudades localizadas a lo largo de la frontera entre Brasil y Uruguay (Benedetti, 2014).

Los datos recopilados mediante la aplicación de la matriz de observación y el examen de las imágenes suministradas por Google Earth para cada localidad tiene limitaciones claras de alcance y cobertura. Sin embargo, el enfoque pedagógico en el que se apoya y la información producida por su aplicación ha demostrado su potencial para generar representaciones precisas de los procesos de fronterización y de sus implicaciones para lugares de frontera remotos tanto geográficamente como contextualmente. En general, la actividad de enseñanza-aprendizaje discutida explo- 
ta el nexo entre investigación y enseñanza en la educación a nivel universitario para involucrar a los estudiantes en la producción de su propio conocimiento. Mediante la generación de información de primera mano, y su contextualización vía la aplicación de conceptos discutidos en clase, se promueve la apropiación del conocimiento y enriquece la experiencia del estudiante como actor activo del proceso enseñanza-aprendizaje. Conectar la enseñanza y la investigación también ofrece a los estudiantes experiencias directas e inmersivas que facilitan la vinculación de los eventos observados con teorías particulares, al tiempo que promueven una comprensión más profunda de los problemas fronterizos complejos. En última instancia, esto ayuda a los estudiantes a convertirse en investigadores críticos capaces de discriminar entre impresiones teóricas y empíricas de las fronteras en función de la capacidad de estas teorías y datos para representar la complejidad y el dinamismo observados durante el proceso de investigación.

\section{Referencias}

AGNEW, J. Borders on the mind: re-framing border thinking. Ethics \& Global Politics, v. 1, 2008. p. 175-191.

ANDERSON, J.; O'DOWD, L.; WILSON, T. M. Why study borders now?, v. 12, 2002. p.1-12-202

ARREOLA, D. D. Border-city idee fixe. Geographical Review, v. 86, 1996. p. 356-369.

BALIBAR, E. Politics and the Other Scene, New York: Verso, 2002.

BENEDETTI, A. Espacios fronterizos del sur sudamericano: Propuesta de un modelo conceptual para su estudio. Estudios fronterizos, v. 15, 2014. p. 11-47.

BRAMBILLA, C. Exploring the critical potential of the borderscapes concept. Geopolitics, v. 20, 2015. p. 14-34.

BUSTAMANTE, J. Frontera México-Estados Unidos. reflexiones para un marco teorico. Frontera Norte, v. 1, 1989. p. 7-24.

BUURSINK, J. The binational reality of border-crossing cities. GeoJournal, v. 54, 2001. p. 7-19.

DA COSTA BRAGA, A.; RIGATTI, D. International conurbations along Brazil-Uruguay border: how ambiguity drives spatial patterns and social exchange. In:DANIEL KOCH; L. M. A. J. S. (Ed.) Proceeding of 7th Interna- 
tionalspace Syntax Symposium. Stockholm: KTH, 2009. p. 1-13.

DORFMAN, A.; COLEN FRANÇA; A. B.; FRANÇA, R. F. 2017. Political commodities and sovereignty management: cigarette smuggling across Brazil's Southern Borders. Geopolitics, 22, 2017. p. 863-886.

FUENTES, C. M. Urban function and its effect on urban structure: the case of Ciudad Juárez, Chihuahua. Journal of Borderlands Studies, 15, 2543, 2000.

GRISWOLD, D. C. R. The treaty of Guadalupe Hidalgo. In: MARTINEZ, O. (ed.) US-Mexico borderlands: historical and contemporary perspectives. SR Books, 2006.

HANSON, G. H. U.S.-Mexico integration and regional economies: evidence from border-city pairs. Journal of Urban Economics, v. 50, 2001. p. 259-287.

HERZOG, L. A. The transfrontier organization of space along the U.S.-Mexico border. Geoforum, 22, 1991. p. 255-269.

HEYMAN, J. 2012. Culture theory and the U.S.-Mexico border. In: WILSON, T.; HASTINGS, D. (eds.) A Companion to Border Studies. Wiley-Blackwell, 2012.

JAMES, I. This mexican city was transformed by factories. Its People Pay a Heavy Price. The Desert Sun, Palm Springs, 2018.

LARA-VALENCIA, F. Quality of life in the United States-México border region, current status and emerging trends. In: WILSON, C.; LEE, E. (eds.) The State of the Border Report, A Comprehensive Analysis of the US-México Border. Washington, DC: Woodrow Wilson Center for International Scholars, 2013.

LARA-VALENCIA, F. Socio-spatial domains of cross-border integration: systematicobservation matrix. Tempe: Arizona State University, 2018.

MAGRI, A., RODRIGUEZ, A.; GALASO, P.; GOINHEIX, S. Entre lo local y lo regional: ciudades de frontera en integración regional transfronteriza en Uruguay. In: MAZZEI, E. (ed.) Las sociedades fronterizas: visiones y reflexiones. Uruguay: Centro de Estudios de la Frontera, 2017.

MEZZADRA, S.;NEILSON, B. Border as Method, or, the Multiplication of Labor, Duke University Press, 2013.

MOREHOUSE, B. Theoretical approaches to border spaces and identities. In: PAVLAKOVICH-KOCHI, V.; MOREHOUSE, B. J. (eds.) Challenged borders: transcending political and cultural boundaries. Ashgate, 2004.

MOYANO, A. Gadsen Purchase. In: MARTINEZ, O. (ed.) US-Mexico Bor- 
derlands: historical and contemporary perspectives. SR Books, 2006. NUGENT, P. Border Towns and Cities in Comparative Perspective. In: WILSON, T.; HASTINGS, D. (eds.) A Companion to Border Studies. Wiley-Blackwell, 2012.

OBERLE, A. P.; ARREOLA, D. D. Mexican medical border towns: a case study of algodones. Baja California. Journal of Borderlands Studies, 19, 2004. p. 27-44.

ODONE, N.; SARTORI DE ALMEIDA PRADO, H. Free shops en Zonas de Fronteras del Mercosur: oportunidad o desafío para la integración a las luz de la reciente legislación brasileña. Tempo do Mundo, v.1, 2015. p. 105-119.

PAASI, A. The changing discourses on political boundaries. Mapping the backgrounds, contexts and contents. In: VAN HOUTUM, H., KRAMSCH, O.; ZIERHOFER, W. (eds.) B/Ordering space. Farnham: Ashgate, 2005. POUNDS, N. J. G. Political Geography. Kogakusha Company, 1963. REY, L. A. Atlantida. Buenos Aires, 1948. RODRÍGUEZ MIRANDA, A. La frontera Uruguay-Brasil y el desarrollo local. Nóesis. Revista de Ciencias Sociales y Humanidades, v. 19, 2010.

RUSSELL, E. 9 things to know about Google's maps data: beyond the map. Google Maps Platform [Online], 2019. Disponível em: https://cloud.google.com/blog/products/maps-platform/9-things-know-about-googlesmaps-data-beyond-map. Acesso em: 15 de maio de 2020.

SASSEN, S. Territory, authority, rights: from medieval to global assemblages. New York: Princeton University Press, 2008.

SCOTT, J. Europen politics of borders, border symbolism, and cross-border cooperation. In: WILSON, T.; HASTINGS, D. (eds.) A companion to border studies. Wiley-Blackwell, 2012.

SOHN, C.; LARA-VALENCIA, F. Borders and cities: perspectives from north america and europe. Journal of Borderlands Studies, v. 28, 2013. p. 181-190.

TAGIL, S.. The question of border regions in Western Europe: an historical background. West European Politics, 5, 1982. p. 18-33.

TAPIA LADINO, M. Borders, mobility and the transborder space: reflections for a discussion. Estudios Fronterizos, v. 18, 2017. VANDEVIVER, C. Applying Google Maps and Google Street View in criminological research. Crime Science, v. 3, 2014. 